\title{
Regulation and control in cooling systems of internal combustion engines
}

\author{
Vladimir Zhukov ${ }^{1}$, Olesya Melnik ${ }^{1}$, Nikita Logunov $^{2}$, and Sergei Chernyi ${ }^{3, *}$ \\ ${ }^{1}$ Admiral Makarov State University of Maritime and Inland Shipping, ul. Dvinskaya, 5/7, \\ 198035, St. Petersburg, Russia \\ 2 Bauman Moscow State Technical University, ul. Baumanskaya 2-ya, 5/1, 105005, \\ Moscow, Russia \\ ${ }^{3}$ Kerch State Maritime Technological University, ul. Ordzhonikidze, 82, 298309, Kerch, \\ Russia
}

\begin{abstract}
The paper is devoted to the urgent problem of improving the automatic regulation of the thermal state of internal combustion engines and controlling the water-chemical cooling regimes during the transition to high-temperature cooling. Principal and functional diagrams of cooling systems with improved control are presented. The prospects of controlling the pressure in the internal circuit of high-temperature engine cooling systems and the automatic control of the physicochemical characteristics of the coolant have been proved.
\end{abstract}

\section{Introduction}

In recent years, the main and traditional trends in the development of engine building are the increase in the aggregate power of internal combustion engines (ICE) due to their forcing by the average effective pressure and rotational speed of the crankshaft and the increased use of electronic control systems. Forcing of ICE is accompanied by an increase in thermal and mechanical loads on the details of the cylinder-piston group, the gas distribution mechanism, other mechanisms and devices of the main engine systems. A prerequisite for ensuring the reliability of ICE is the compliance of the parameters of the fuel supply, pressurization, lubrication and cooling operation mode of the engine. The selection and provision of the required system parameters during operation is carried out by automatic regulation and control systems. The modern level of development of science and technology makes it possible to use automatic regulators with electronic control to regulate various parameters of ICE. Most widely, such devices are used in the fuel supply systems of modern engines, providing control of the cyclic fuel supply, injection timing angle, the law of fuel supply and gas distribution mechanisms for changing gas exchange phases. Improving regulation and control systems through the use of microprocessor devices is a promising direction for the development of ICE. The studies were aimed at improving

\footnotetext{
*Corresponding author: sergiiblack@gmail.com
} 
automatic systems for controlling the thermal state of ICE and controlling the parameters of engine cooling in order to ensure their reliability with increasing thermomechanical loads.

The purpose of the ICE cooling system is to provide an optimal and stable thermal state of its parts and assemblies. Such temperature should be considered optimum, at which the materials of the parts retain their strength properties, engine oils retain high lubricity and load-bearing ability, and heat loss through the cooling system is minimal. Maintaining the optimum temperature level of marine diesel engines can be achieved by improving regulation methods and introducing regulation and control systems that implement these methods. When creating such systems, it is necessary to take into account the tendency to increase the temperature level of ICE cooling [1, 2] and the ever-wider introduction of high-temperature cooling systems (HTCS), which provide an increase in the economic and resource indicators of diesel engines [3-6]. The work [7] provides information on engines of such manufacturers as MAN B\&W Diesel Ltd, Caterpillar, General Motors, Wartsila/Sulzer, Deutz AG, Barnaultransmash OJSC, in the power range from 110 to 3680 $\mathrm{kW}$, with cylinder diameters from 146 to $457 \mathrm{~mm}$, and a crankshaft speed of 277 to 2200 $\mathrm{rpm}$. The coolant temperature of the internal circuit of these engines is from 115 to $126^{\circ} \mathrm{C}$. These data confirm that HTCS are successfully used on small-, medium- and high-speed engines of various sizes. The tendency to expand the use of HTCS for diesel engines must be taken into account when upgrading the automatic regulation and control systems of internal combustion engines, while it is necessary to separate the parameters that need to be regulated, i.e. to maintain at a given constant damage, and the parameters that should be controlled depending on the engine operating mode.

\section{Problem Statement}

The vast majority of modern marine diesels are equipped with a dual-circuit cooling system, the principal diagram of which is shown in Fig. 1. The functioning of the dualcircuit liquid cooling systems of ICE is characterized by two groups of parameters [8]: regime and water-chemical. The first group includes the temperature of the coolant at the inlet of the engine $T_{\text {coolant }}^{r}$ and at the outlet of the engine $T_{\text {coolant }}^{\text {s }}$, the temperatures at the inlet and outlet of the outboard line, respectively, as well as the pressure in the cooling system $p_{0}$, the mass flow rate $G_{\text {coolant }}$, the temperature difference in the cooling circuit $\Delta T$, which determine the heat flux density $q_{\text {cool }}$ through cooled surfaces, and the amount of heat removed through the cooling system $Q_{\text {cool }}$. The main ones should be considered the temperature of the coolant $T_{\text {coolant }}$ and associated with it, in the case of high-temperature cooling, pressure in the cooling system $p_{\mathrm{cs}}$. It has been established that for each type of engine, there is a certain relatively narrow range of coolant temperatures, at which a combination of high power and economic indicators with sufficient durability and reliability is provided. 


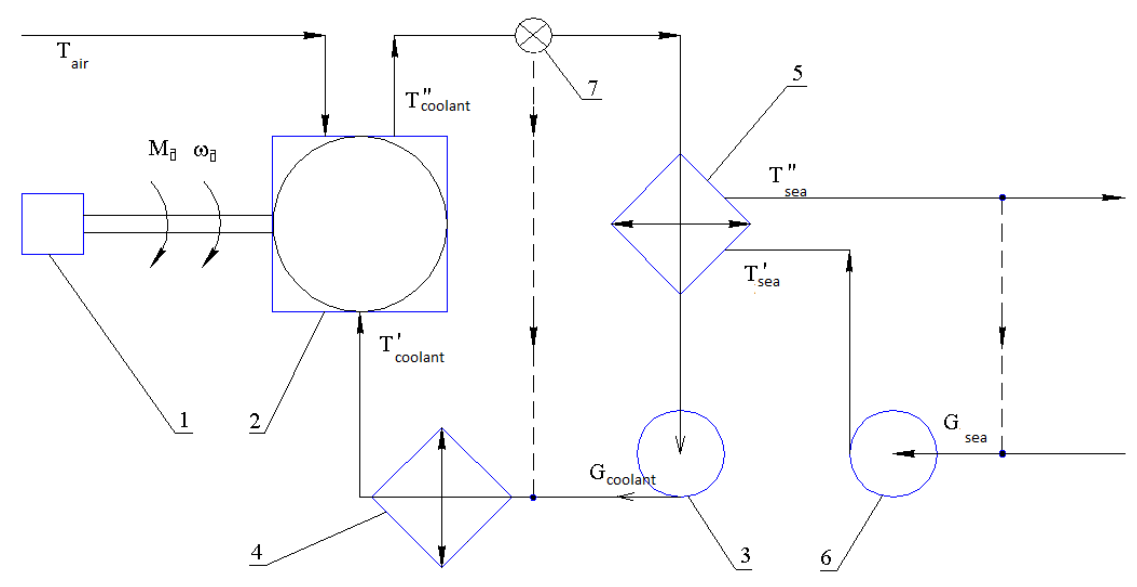

Fig. 1. Principal diagram of a dual-circuit cooling system for marine diesel: 1 - load unit, 2 - piston of ICE, 3 - internal circuit circulation pump, 4 - oil-water cooler, 5 - water-to-water cooler, 6 - external circuit circulation pump, 7 - thermostat. $\omega_{\varepsilon}$ - engine crankshaft speed, $M_{\varepsilon}$ - engine torque, $T_{\text {air }}$ intake air temperature, $T_{\text {coolant }} T_{\text {coolant }}$ - coolant temperature at the engine inlet and outlet, respectively, $T_{s e a^{\prime}} T_{s e a}$ - the temperature of the seawater at the inlet and outlet of the water-to-water cooler, respectively, $G_{\text {conlent }}, G_{\text {sea }}$ - mass flow rates of the internal circuit coolant and seawater, respectively

The main characteristic of the water-chemical regime, which determines the intensity of cavitation-corrosion damage, is the hydrogen index $\mathrm{pH}$ of the coolant [9], [10]. The most effective way to control the hydrogen index of ICE coolants is to introduce additives into the cooling system [11]. With an increase in the temperature level of cooling systems, special attention must be paid to protecting their elements from corrosion damage.

Thus, the use of HTCS leads to toughening the requirements for both regulating the thermal state of the diesel engine and controlling the water-chemical parameters of cooling. Deviation from the specified cooling parameters inevitably leads to the formation of a vapor film on the cooled surfaces, the deposition of corrosion products on the cooled surfaces and, as a consequence, overheating of the engine, a sharp decrease in resource and economic indicators.

Marine diesel engine as an object of regulation by thermal state should be considered as a multi-factor, multi-parameter, dynamic, stochastic object, the control of which requires complex approaches and methods, examples of which are presented in [12-14].

In modern ICE cooling systems, the Polzunov-Watt control principle is implemented. It means that the temperature of the coolant at the engine outlet is regulated, while the regulatory actions are generated based on the measurement of the adjustable parameter, i.e. the same temperature.

When analyzing the regulation processes, it is necessary to take into account that during operation, the engine is affected by three main external factors: crankshaft rotation speed $\omega$, load $N$, intake air temperature $T_{\text {air }}$.

To describe the processes of automatic regulation, functional schemes of the objects of regulation are used, on which the input and output parameters and external influences on the object of regulation are depicted. Functional diagrams of marine diesel as an object of regulation by thermal state are shown in Fig. 2 
a)

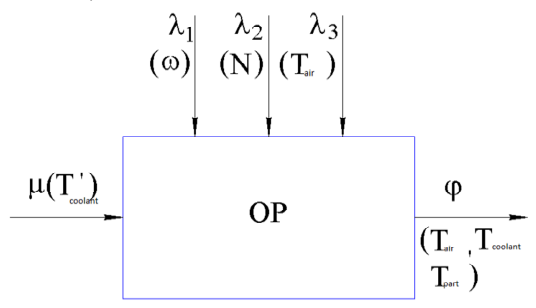

b)

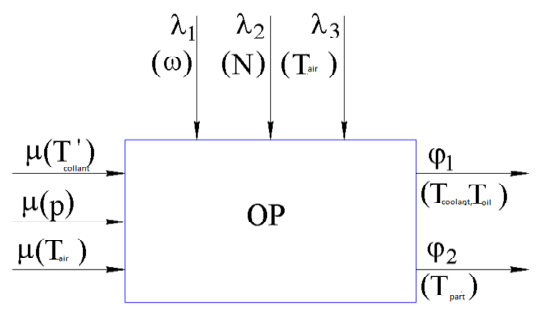

Fig. 2. Functional diagrams of thermal control systems for internal combustion engines: a) onedimensional, b) multidimensional

For most modern ICEs, a one-dimensional control system is typical (Fig. 2 a), in which the control object is the temperature of the coolant. For promising HTCS, multidimensional control systems of fig. 2 b) is advisable, in which the output parameters are the temperatures of the part to be cooled, the temperature of which $T_{\text {part }}$ limits the reliability of the engine, coolant $T_{\text {coolant }}$ and engine oil $T_{\text {oil }}$. The number of regulatory actions $\mu_{i}$ in such systems should be no less than regulated parameters, which can be both the temperature of the coolant and the pressure in the cooling system, lubrication, pressurization. Regulation of the thermal state of the internal combustion engine must be carried out depending on the load and speed conditions of the engine.

The control of water-chemical cooling regimes should be carried out in order to maintain the specified physical and chemical properties of the coolant for a long period of operation.

\section{Results}

Maintaining the optimal thermal state of the engine can be ensured if the regulation of the temperature of the coolant $\mathrm{T}_{\text {coolant }}$ is supplemented by the regulation of the temperature of the most heat-loaded part $\mathrm{T}_{\text {part }}$. In this case, two regulatory actions should be implemented. One of the actions may be controlled pressure in the cooling system. It is proposed to control the pressure in the cooling system depending on the engine operating mode using the device described in [15].

Static and dynamic characteristics of a cooling system with temperature control of a coolant are considered in detail in [16]. Cyclic changes in the temperature of the working fluid lead to changes in the temperature of the cylinder wall surface during the cycle by 7 $10{ }^{\circ} \mathrm{C}$, which extend to a depth of $2-4 \mathrm{~mm}$ [17]. The outer temperature of the cylinder liner remains almost constant, and the heat transfer process in the liquid cooling jacket can be considered as quasistatic.

The amount of heat given off by the cooled surfaces of the parts to the coolant is determined by the Newton-Richman equation

$$
Q=\alpha F_{\text {part }}\left(\mathrm{T}_{\text {part }}-\mathrm{T}_{\text {av.coolant }}\right)
$$

where $\alpha$ - heat transfer coefficient, $F_{\text {part }}$ - area of the cooled surface of the part, $T_{\text {part }} T_{\text {avisolant }}$-average temperatures of a part and coolant, respectively.

The heat transfer coefficient depends on the nature of heat transfer at the wall-liquid interface, the temperature of the wall $T_{\text {part }}$ and the liquid $T_{\text {avcoolant }}$, the pressure in the 
system $p$ and the speed of the liquid relative to the wall $w$. Thus, the specific heat flux supplied from the wall to the liquid can be represented as a function

$$
q_{\text {sup }}=f\left(T_{\text {part }} T_{\text {avicoulant }} p_{t} w\right)
$$

The amount of heat removed by the coolant of the internal circuit to the seawater in the water-to-water cooler is determined by the equality

$$
q_{\text {rem }}=c_{\text {coolant }} G_{\text {coolant }}\left(T_{\text {coolant }}^{\pi}-T_{\text {coolant }}^{r}\right)
$$

where $c_{\text {coolant }}$ - specific heat of the coolant, $G_{\text {coolant }}-$ mass flow rate, $T_{\text {coolant }}^{\text {sf }} T_{\text {coolamt }}^{s}$ - temperature of the liquid at the outlet and inlet of the cooler, respectively.

The flow rate depends on the position of the regulating body (thermostat valve) $g$, so the amount of heat removed can be represented as a functional dependence

$$
q_{\mathrm{ram}}=f\left(c_{\text {codant }} \cdot g, T_{\text {coolant }}^{\mathrm{m}}, T_{\text {coolant }}^{r}\right)
$$

In the steady state, the following equality is valid

$$
q_{\text {sup }}=q_{\mathrm{ram}} \text {. }
$$

After the expansion of dependencies (2) and (4) in a Taylor series and subsequent linearization, we obtain:

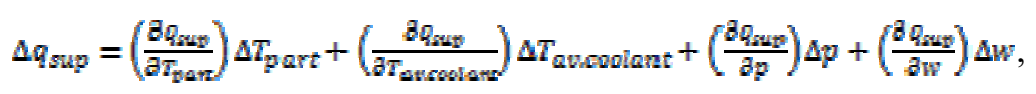

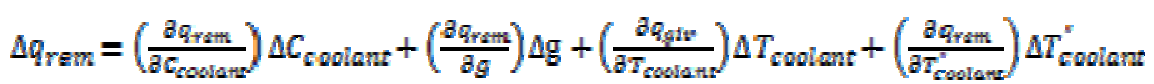

The fluid flow rate $w$ and its mass flow rate are functions of the crankshaft rotation speed $\omega$, from which the circulation pump is driven and the thermostat regulator is moved $h: w=f(\omega, h), g=f(\omega, h)$.

The expansion of these functions in a Taylor series and subsequent linearization allow obtaining:

$$
\begin{aligned}
& \Delta w=\left(\frac{\partial w}{\partial \omega}\right) \Delta \omega+\left(\frac{\partial w}{\partial h}\right) \Delta h \\
& \Delta g=\left(\frac{\partial g}{\partial \omega}\right) \Delta \omega+\left(\frac{\partial g}{\partial h}\right) \Delta h
\end{aligned}
$$

After substituting expressions (8) and (9) into equations (6) and (7), respectively, and subsequent transformations carried out under assumptions that $T_{\text {av.conlant }}=$ const, $c_{\text {coolant }}=$ const,$T_{\text {coolant }}^{r}=$ const, we obtain

$$
\Delta q_{\text {sup }}=\left(\frac{\partial q_{\text {sut }}}{\partial T_{\text {van }}}\right) \Delta T_{\text {part }}+\left(\frac{\partial q_{\text {suv }}}{\partial p}\right) \Delta p+\left(\frac{\partial q_{\text {suv }}}{\partial \omega}\right) \Delta \omega+\left(\frac{\partial q_{\text {suv }}}{\partial h}\right) \Delta h
$$




$$
\Delta q_{\mathrm{ram}}=\left(\frac{\partial q_{\mathrm{ram}}}{\partial \omega}\right) \Delta \omega+\left(\frac{\partial \mathrm{qram}}{\partial \hat{n}}\right) \Delta h+\left(\frac{\partial q_{\mathrm{ram}}}{\partial T_{\text {coulant }}}\right) \Delta T_{\text {coolant }}
$$

To obtain the differential equation of the engine as a regulated object according to the temperature of the most heat-loaded part, it is necessary to use the equality

$$
C\left(\frac{d T_{\text {parr }}}{d t}\right)=q_{\text {sup }}-q_{\text {rem }}
$$

Since at unsteady thermal conditions $T_{\text {part }}=T_{\text {parto }}+\Delta T_{\text {part }}, q_{\text {mp }}=q_{\text {wpo }}+\Delta q_{\text {mp }}$, $q_{\text {rem }}=q_{\text {remo }}+\Delta q_{\text {rem }}$, then, taking into account equality (5), equation (12) takes the form

$$
C\left(\frac{d \Delta T_{p a r r}}{d t}\right)=\Delta q_{\text {sup }}-\Delta q_{\text {rem }}
$$

Substituting equations (10) and (11) into equation (13) allows us to write the following

$$
\begin{aligned}
& C\left(\frac{d \Delta T_{p a r k}}{d t}\right)=\left(\frac{\partial q_{r u p}}{\partial T_{p a r t}}\right) \Delta T_{\text {part }}+\left(\frac{\partial q_{\mathrm{sup}}}{\partial p}\right) \Delta p+\left(\frac{\partial q_{\mathrm{gup}}}{\partial \omega}\right) \Delta \omega+\left(\frac{\partial q_{\mathrm{rup}}}{\partial h}\right) \Delta h-\left(\frac{\partial q_{\mathrm{ram}}}{\partial \omega}\right) \Delta \omega-
\end{aligned}
$$

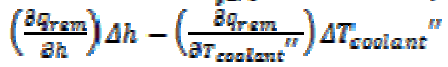

The combination of values of the rotational speed of the crankshaft $\omega$ and the position of the control element of the thermostat $h$ characterize the mode of operation $R$ and the load on the cooling system.

With this in mind, equation (14) takes the form

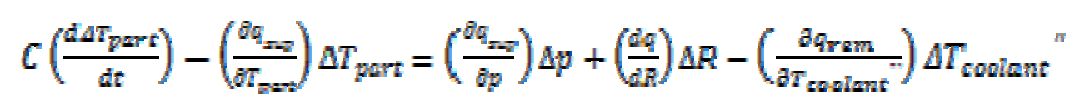

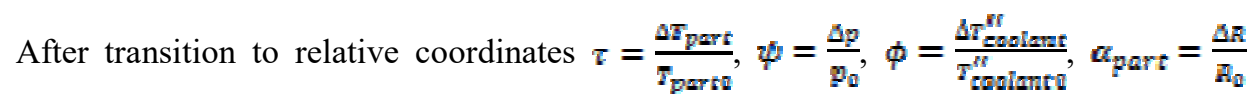
and dividing all the terms of equation (15) by the coefficient $\psi$, equation (15) takes the form

$$
T_{\text {part }} \frac{d z}{d \tau}+\theta_{t} \phi=\psi+\theta_{p} \tau+\theta_{\text {part }} \alpha_{\text {part }}
$$

The resulting differential equation can be used to conduct a numerical experiment to determine the effect of pressure changes in the cooling system, expressed through the dimensionless coordinate $\psi$, on the temperature of the most heated part and the temperature of the coolant at the engine outlet, i.e. in the implementation of two-dimensional regulation of the thermal state of ICE.

In existing ICE cooling systems, the process is based on the automatic maintenance of a given temperature of the coolant at the outlet of the engine without taking into account the temperature of the cooled surfaces and the nature of heat transfer.

In modern forced marine diesel engines with HTCS, heat transfer in cooling cavities is carried out, as a rule, in the mode of bubble boiling of underheated liquid. From an energy point of view, heat transfer in the conditions of bubble boiling is the most advantageous, since due to the high heat transfer coefficient, intense heat transfer from the cooled surfaces at low flow rates is ensured. However, during the operation of marine diesels with increased loads, as well as at elevated ambient temperatures and seawater, a transition from 
bubble to film boiling is possible with a sharp decrease in the heat transfer coefficient, which can lead to overheating of the engine and its failure. The proposed automatic control model eliminates the possibility of engine overheating.

In liquid cooling systems with a normal temperature level (the temperature at the engine outlet is $80-85^{\circ} \mathrm{C}$ ), the expansion tank serves to store the supply of coolant and provides the possibility of thermal expansion of the liquid with increasing its temperature. For the implementation of the control action on pressure in the cooling system, it is necessary to use a sealed expansion tank with an improved design [18]. Due to the expansion tank being sealed, it becomes possible to create increased presure in the tank using a pressure reducing valve through which air compressed in the compressor is supplied to the tank.

The introduction of a control unit with a sensor system provides pressure control both in the expansion tank and in the cooling system as a whole. The choice of pressure increase is carried out automatically, depending on the operating mode of the marine diesel engine. A compressor forcing air into the expansion tank can increase the pressure in the cooling system to $0.2-0.3 \mathrm{MPa}$, as a result of which it becomes possible to increase the temperature of the coolant in the internal circuit to $120-130{ }^{\circ} \mathrm{C}$. The increase in pressure in the internal circuit eliminates the possibility of film boiling in the cooling cavities of the engine and prevents the failure of the diesel engine due to its overheating.

The ICE cooling system scheme in which it is possible to control the pressure in the internal cooling circuit is shown in Fig. 3 [19].

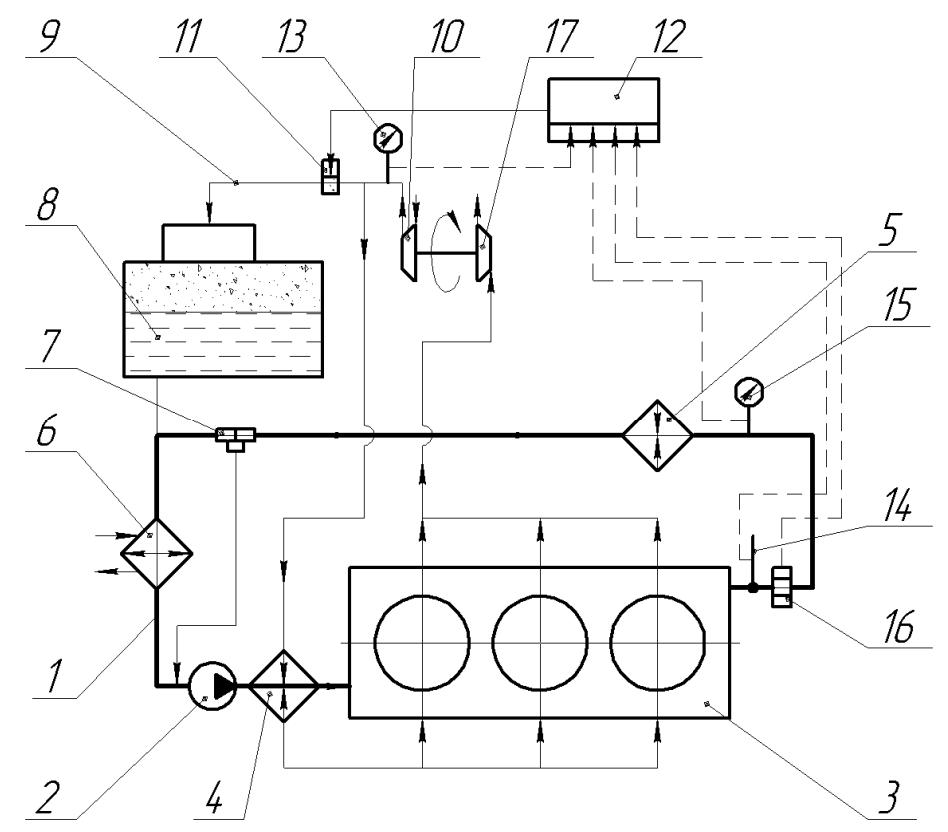

Fig. 3. The scheme of the cooling system with the ability to control pressure in the internal circuit: 1 internal circuit of the cooling system, 2 - circulation pump, 3 - piston cooling jacket, 4 - charge air cooler, 5 - oil-water cooler, 6 - water-to-water cooler, 7 - thermostat, 8 - expansion tank, 9 - air line, 10 - compressor, 11 - pressure reducing valve, 12 - control unit, 13 - boost pressure sensor, 14 coolant temperature sensor at the engine outlet, 15 - pressure sensor in the cooling system, 16 optical sensor for the presence of vapor phase in the coolant, 17 - turbine.

The control of the water-chemical modes of ICE cooling can be ensured by automating the control and correction of the required properties of the coolant due to the controlled introduction of additives into the coolant (Fig. 4) [20]. 
The pressure drop in the cooling jacket allows assessing the degree of destruction of macromolecules of water-soluble polymers and micellar formations of surfactants that are part of the additives. The control action on the metering needle valve 12 is generated by comparing the information received in the control unit 13 from the sensors and the required values of the quality indicators of the coolant stored in its memory. As an analyzer of the chemical properties of the coolant, one can use the Multitest IPL-513 or Multitest KSL-101 instruments, which allow determining the hydrogen index $(\mathrm{pH})$ of the liquid, hardness, and total salinity.

The presented cooling system provides continuous and operational quality control of the coolant and, if necessary, automatic restoration of its operational properties. Compared with existing cooling systems, the proposed system facilitates the maintenance of internal combustion engines and increases their reliability.

The principle of operation of the upgraded ICE cooling systems is described in detail in $[21,22]$.

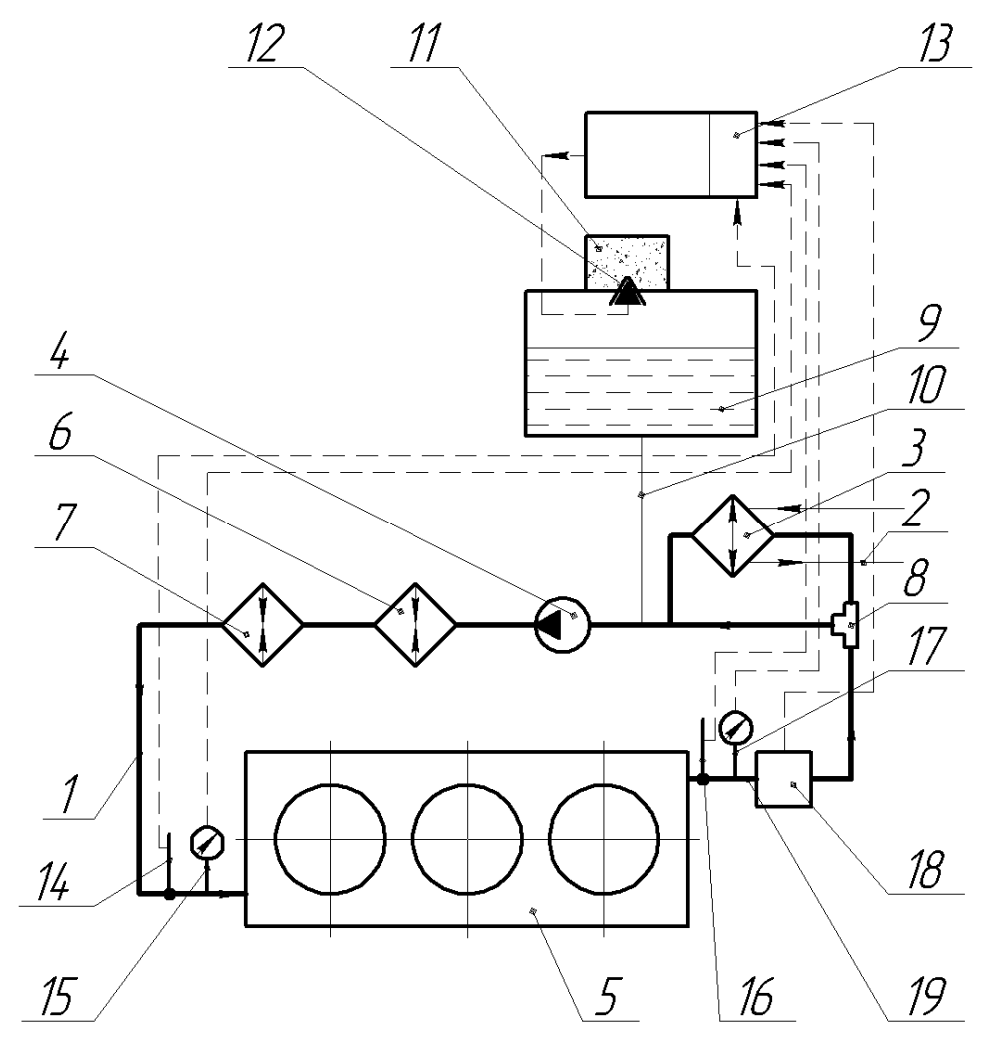

Fig. 4. Cooling system with automatic correction of coolant properties: 1 - closed circuit, 2 - open circuit, 3 - water-to-water cooler, 4 - circulation pump, 5 - cooling jacket, 6 - charge air cooler, 7 - oilwater cooler, 8 - thermostat, 9 - expansion tank, 10 - suction pump line 11 - container with additive concentrate, 12 - needle valve, 13 - control unit, 14, 16 - temperature sensors, 15, 17 - pressure sensors, 18 - analyzer of chemical properties of the coolant, 19 - discharge pipe.

As the control unit in the proposed systems, it is possible to use a programmable microprocessor, for example ATMega8 or PIC16F1823, which will allow adjusting the pressure in the cooling system depending on the engine operating mode according to the program stored in the control unit and the additive entering the cooling system depending on the physicochemical properties of the coolant. 


\section{Conclusions}

Compared with the traditional cooling systems of ICE with one-dimensional regulation, which are widely used at present, offered HTCS realize the principle of multidimensional and multifactor automatic regulation of the thermal state of a diesel engine and control of water-chemical cooling modes. Improving regulation and control in the cooling system eliminates the transition of bubble boiling modes in cooling cavities to film boiling modes, as well as protecting cooled surfaces from corrosion and erosion damage. Thus, an increase in the reliability of internal combustion engines at maximum loads and at elevated temperatures is provided.

The studies confirm the relevance of continuing scientific research aimed at improving the cooling modes of marine diesel engines, modernizing the design of cooling systems, optimizing the processes of automatic regulation of the thermal state of marine diesel engines in operating conditions. Further improvement of such systems should be directed to the development of optimal laws for controlling the cooling parameters depending on the engine operating conditions and the introduction of the programmable controllers into automatic control systems of the thermal state of the internal combustion engine and control systems of the water-chemical parameters of cooling.

\section{References}

1. S. Schneider, J. Stehlig, A. Eilemann, Auto Tech Review 3(9), 46-51 (2014).

2. M. Shatrov, T. Krichevskaya, A. Yakovenko, A. Solovyev, Advances in Intelligent Systems and Computing, vol. 916, 333-343 (2019).

3. V. Zhukov, A. Pulyaev, O. Melnik, A. Nyrkov, 2019 IEEE Conference of Russian Young Researchers in Electrical and Electronic Engineering (EIConRus) pp. 385-388. IEEE (2019).

4. O. Bezyukov, V. Zhukov, O. Zhukova, Russian Engineering Research 28 (11), 10551057 (2008).

5. C. Cheng, C. Cheung, T. Chan, S. Lee, C. Yao, K. Tsang, Fuel, 87(10-11), 1870-1879 (2008).

6. J. Pastor, J. García-Oliver, J. Pastor, J. Ramírez-Hernández. Fuel 90(4), 1556-1566 (2011).

7. C. Barros, N. Peypoch, Energy Economics 30(6), 3118-3127 (2008).

8. J. Abdulhamid, International Journal of Science and Research (IJSR) 5(1), 1541-1544 (2016).

9. J. Girtler, Journal of Polish CIMAC 4(1), 29-40 (2009).

10. B. Tansel, Recent patents on chemical engineering 1(1), 17-26 (2008)..

11. Anon, Anti-Corrosion Methods and Materials, 48(3) (2001).

12. B. Valdez, M. Schorr, R. Zlatev, M. Carrillo, M. Stoytcheva, L. Alvarez, N. Rosas, Environmental and Industrial Corrosion - Practical and Theoretical Aspects (2012).

13. M. Nekooei, J. Jaswar, A. Priyanto, Jurnal Teknologi, 74(5), 121-124 (2015).

14. J. Bradish, P. Myers, O. Uyehara, SAE Transactions, 633-650 (1967).

15. A. Zhelezniak, L. Bezmennikova, V. Zhukov, V. Erofeev, Journal of Physics: Conference Series, 803(1), 012184 (2017).

16. N. Chigrinova, O. Kuznechik, V. Chigrinov, Journal of Engineering Physics and Thermophysics, 77(3), 578-589 (2004)..

17. Y. Yildiz, A. Annaswamy, D. Yanakiev, I. Kolmanovsky, 2007 American Control Conference, 3700-3705. (2007)

18. F. Barchenko, V. Bakulin, Journal of Engineering Physics and Thermophysics, 90(3), 657-664 (2017). 
19. A. Ouroua, L. Domaschk, J. Beno, IEEE Electric Ship Technologies Symposium, 7074, (2005).

20. O. Bezyukov, V. Zhukov, O. Zhukova, Russian Engineering Research, 28(11), 10551057 (2008).

21. P. Punov, T. Evtimov, R. Chiriac, A. Clenci, Q. Danel, G. Descombes, Energy for A Better Environment and Improved Sustainability 1, 995-1016, (2018).

22. V. Alpatov, A. Soloviev, MATEC Web of Conferences 196, 01008 (2018). 